\title{
The Quantified Animal: Precision Livestock Farming and the Ethical Implications of Objectification
}

\author{
Jacqueline M. Bos ${ }^{1}$ (D) Bernice Bovenkerk ${ }^{1} \cdot$ Peter H. Feindt ${ }^{2} \cdot$ Ynte K. van Dam $^{1}$
}

Accepted: 1 November 2018 / Published online: 27 November 2018

(C) The Author(s) 2018

\begin{abstract}
Precision livestock farming (PLF) is the management of livestock using the principles and technology of process engineering. Key to PLF is the dense monitoring of variegated parameters, including animal growth, output of produce (e.g. milk, eggs), diseases, animal behaviour, and the physical environment (e.g. thermal micro-environment, ammonia emissions). While its proponents consider PLF a win-win strategy that combines production efficiency with sustainability goals and animal welfare, critics emphasise, inter alia, the potential interruption of human-animal relationships. This paper discusses the notion that the objectification of animals by PLF influences the developmental pathways of conventional industrial farming. We conduct a conceptual analysis of objectification by comparing discussions in feminist ethics and animal ethics. We find that in animal ethics, objectification includes deontological arguments regarding instrumentalisation, de-animalisation, alienation, commodification and quantification of animals. The focus on socio-political context and relationality connects these debates to central ideas in care ethics. We adopt a care ethics perspective to assess the implications of the objectification of animals in livestock farming. The basic claim is that sensory knowledge symbolised by the farmers' unity of hand, head and heart would make it harder to objectify animals than abstract and instrumental reasoning where the pursuit of knowledge is intertwined with the pursuit of control, as in mainstream PLF. Despite of what can be considered as a good caring relationship between farmers and animals that is mediated by PLF, people involved in conventional industrial farming still seem to become further detached from farmers and animals, because the PLF system itself is objectifying. PLF redefines the notion of care, in terms of data transparency, standardisation of methods for analysis, real-time collection and processing of data, remote control, and the use of digital platforms. This creates new expectations and requires a redistribution of responsibilities within a wider scope of relations in the value chain.
\end{abstract}

Keywords Precision livestock farming · Objectification · Animal ethics · Care ethics · Humananimal relationships

Jacqueline M. Bos

jacqueline.bos@wur.nl; jacqbos@gmail.com

Extended author information available on the last page of the article 


\section{Introduction}

Precision livestock farming (PLF) is an emerging field that can be defined as the management of livestock production using the principles and technology of process engineering (Wathes et al. 2008). PLF applies sensors and information technology in livestock to recognise group behavioural patterns, identify individual animals, detect the occurrence of fertility, disease and discomfort, as well as to measure changes between individuals and groups of animals over time (Banhazi and Black 2009; Berckmans 2008; Frost et al. 1997). The PLF approach translates the Precision Agriculture (PA) approach, which has been used in arable farming since the mid-1980s, to farm animal production. PA is based on the assumption that the productivity of agricultural land can vary considerably, even within small patches (less than one hectare). The combined use of drones and tractors with a GPS navigation system can help to implement optimised crop management strategies (Bramley 2009). While PLF and PA share design principles and techniques, livestock production is more complex and ethically sensitive, mostly because now living animals are subjected to automatic monitoring and control systems (Wathes et al. 2008).

At the highest level of abstraction, PLF conceptualises livestock production as a set of interactive processes in a complex network (Berckmans 2008). From an engineer's perspective, the animal is the source of the most important process signals. These need to be measured directly and continuously. On-farm PLF applications, such as sensors and computer models, are rapidly evolving, thereby augmenting the amount and types of data collection and processing (Kühl and Burghardt 2013). The scope of PLF transcends beyond the farm and includes the entire value chain where data is increasingly shared between feed companies, breeders, farmers, and food processors. For example, the Dutch famers' association LTO and EDI-Circle, a federation of agricultural accountants, announced that they would start data collection from various information sources at the farm (Smart Dairy Farming 2017). The use and sharing of the data would be formalised in a Cooperative Datahub, in this case initiated by feed company Agrifim, breeding company CRV and milk processor FrieslandCampina. All data would be collected in a jointly acquired digital platform and an authorization register would allow participating farmers to decide who can use their data and for what purpose (Nieuwe Oogst 2017).

In principle, PLF can incorporate and sustain a broad range of private and societal goals and respond to the changing economic, political and regulatory context that forces agricultural producers to integrate more ambitious environmental, animal welfare and consumer concerns while maintaining high levels of production at low cost (Lowe et al. 2010; Daugbjerg and Feindt 2017). While PLF may render livestock farming more complicated and require significant investments, it may also support more socially viable entrepreneurial pathways. Full implementation of PLF in conventional industrial farming will both require and create an interplay of variegated actors with differential interests, power and imagination. Critical analyses of technology (Feenberg 1999) may play a useful role in the analytical distinction between the specific functionalities of a technology, on the one hand, and the process of integrating new technological arrangements into the social world, on the other. This analytical distinction helps us to make the basic norms and values more explicit, and to locate them either in the PLF technology per se or in the surrounding social structure and institutions (Bos 2008; Feenberg and Callon 2010).

The potential of PLF to influence or reshape practice, meaning and use (Feenberg and Callon 2010) requires a discussion about the possible implications. The meaning of PLF and 
its implications are contested. Proponents from science and industry see PLF as a means to create real-time knowledge, to advance animal health and welfare and to improve business process control, thereby strengthening the conditions for livestock farming (EU-PLF 2017; Berckmans 2014; Banhazi et al. 2012). Their arguments refer to the specific functionalities of PLF regarding the collection and processing of data on living animals in a standardized way for a broad spectrum of applications, including animal welfare. Opponents claim that PLF enables scaling up and mechanization of animal husbandry systems in conventional industrial farming, accelerates the substitution of labour with capital, and disrupts its human-animal relationships: overall, PLF would turn animals into objects (Wakker Dier 2010; NRC 2012). The critics' arguments refer to the integration of PLF in conventional industrial farming systems where animals are potentially harmed by a combination of processes that together lead to the interruption of human-animal relationships.

The normative controversy around PLF indicates that the developmental pathways of this technology are not yet settled (Feenberg 1999). If we want to understand how PLF can incorporate a broader range of societal goals, we first need to address the more fundamental question whether PLF leads to an additional objectification of animals in conventional industrial livestock farming. In this paper, we contribute to this debate by analysing the link between PLF and the objectification. To that end, we develop a three-stage argument. Our first step is to explore the principles of PLF and to identify a number of factors and trends that allow to derive technology-inherent characteristics. This allows us to critically reflect on the underlying assumptions and implications of PLF. Our second step is a conceptual analysis of objectification (Furner 2004). For this purpose, we start with Kantian ethics and then turn to debates in feminist ethics where the underlying assumptions and implications of objectification have been most fully articulated. We then discuss parallels in the animal ethical literature and in care ethics and assess whether the objectification claim is plausible in livestock farming. Our third step is to assess the ethical implications of objectification by PLF in conventional industrial livestock farming. We will suggest that (a) the objectification claim raises the question of what is to be considered a good caring relationship between the farmer and the animal; and (b) that the moral assessment of PLF cannot be settled without consideration of its effects on the caring relationship in specific settings.

\section{Principles of PLF}

PLF can be defined as the management of livestock production using the principles and technology of process engineering (Wathes et al. 2008). PLF applies sensors in livestock to recognise group behavioural patterns, identify individual animals, detect the occurrence of fertility, disease and discomfort, as well as to measure changes of variables in individual animals and groups of animals over time (Banhazi and Black 2009; Berckmans 2008; Frost et al. 1997). From an engineer's perspective, the animal is the source of the most important process data, which should be measured directly and continuously. Variables suitable for the PLF approach include animal growth, the output of milk and eggs, certain endemic diseases, aspects of animal behaviour, and the physical environment of a livestock building, such as its thermal micro-environment and emissions of gaseous pollutants such as ammonia (Wathes et al. 2008). For application at the farm level, data collection and processing must be geared towards generating meaningful instructions for the farmer. The information on livestock and physical environment must be interpreted in a systematic way, specifically through algorithmic 
formalisation (Berckmans and Vandermeulen 2013; Kamphuis and Steneveld 2016). Achieving these goals in PLF demands an interdisciplinary collaboration between animal scientists, process engineers and computer scientists (Kühl and Burghardt 2013).

Recognising that PLF uses the principles of process engineering, the key components in PLF, as shown in Fig. 1, are sensors, a mathematic model, target values for each process or output and a predictive controller (Wathes et al. 2008). PLF as interdisciplinary process design aims to increase knowledge and control of processes inside the animal and across all aspects of the physical environment surrounding the animal. A key step is therefore to define the target values for the different processes and the desired trajectories towards their achievement. This is usually done by the livestock farmer and/or other actors in the value chain with a view to economic, quality and environmental criteria, for example, the delivery of a flock of broiler chickens displaying a defined leanness at a guaranteed live weight on a specific date, and grown within permitted limits on the emission of aerial pollutants, such as ammonia, from the building (Wathes et al. 2008; Berckmans and Vandermeulen 2013). The selection and specification of the target values translate moral values and priorities into the operational guidance values of a specific PLF system.

As shown in Fig. 1, the PLF model allows operators to manage farm animals as individuals in terms of input control, such as feed intake and thermo-physical environment, and output measures, such as movement, rumination, growth, milk yield, discomfort and diseases (Wathes et al. 2008). In the absence of PLF, livestock management decisions will be based almost entirely on the judgement and experience of the livestock farmer, who must estimate or guess the likely effects of any control action, with each of the manifold processes involved controlled separately (Parsons et al. 2007). In PLF, the different input and output aspects in and around the animal are managed and controlled both simultaneously and automatically. Quantification of these aspects provides an objective measure for identifying individual animals or groups of animals. These differentiated data can then be translated into meaningful instructions for the farmer. For example, in animal feeding, PLF enables the farmer to apply a nutritional regime based on accurate predictions for each individual animal or group of animals (Parsons et al. 2007). The measures in PLF consist of animal-based parameters, which is the field of animal

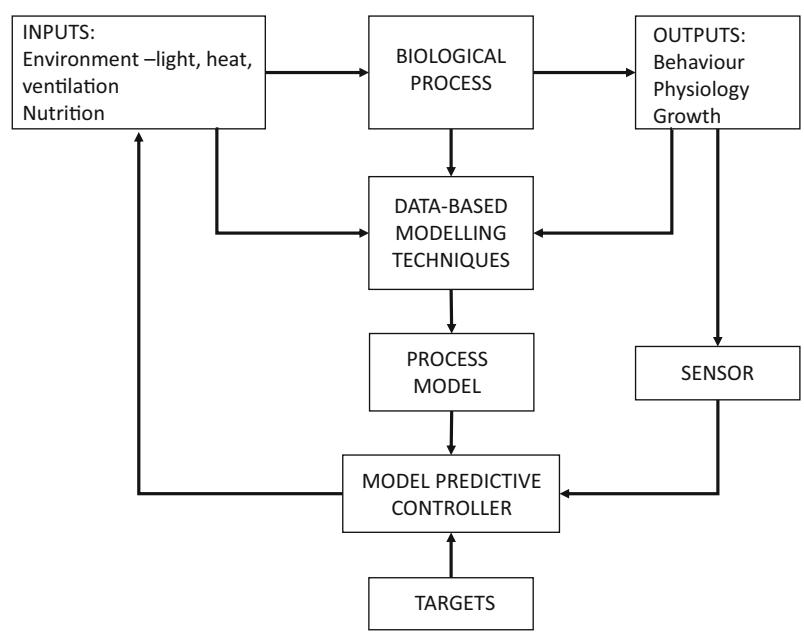

Fig. 1 Schematic overview of the key components in PLF to control biological processes, such as animal behaviour, physiology and growth. Source: Wathes et al. 2008, p. 3 
sciences (Loor et al. 2013). For example, in dairy farming these animal-based parameters include daily milk yield recording, milk component monitoring, pedometers and heat detection monitoring, automatic temperature recording devices, milk conductivity indicators and daily bodyweight measurements (Bewley 2016).

Certain characteristics and applications in PLF make them potentially powerful tools for livestock farming. First, automated data processing facilitates data transparency and standardisation of methods for analysis. Second, sensor technologies are able to collect data continuously over time, compared with the limited, discrete time periods of human observers, whereas computing power and mathematical models allow real-time processing of these data. This enables more complex design aspects in PLF, such as algorithmic formalisation (Kühl and Burghardt 2013). Third, designed user applications on smartphones or laptops in combination with access to wireless internet assist farmers in keeping track of their animals' status without being physically present in the livestock building (Bos and Munnichs 2016). This demonstrates PLF as a user convenience and remote control technology. Fourth, farmers provided with detailed information about animal processes are freed up from routine controls and can therefore spend more time on less repetitive tasks. This demonstrates PLF as labour saving technology (Berckmans 2008; Frost et al. 1997). Fifth, bespoke data collection systems on the farm make it possible to electronically transfer details of animal performance, labour input or financial and environmental performance to a central data hub, where it could then be stored, processed and shared with other actors along the value chain (Smart Dairy Farming 2017). This demonstrates a widening scope and organisation of PLF that allows for the participation of different groups of actors.

\section{Normative Framework}

\section{Two Main Categories of Objectification}

Objectification has two distinct meanings and usages: 'treating as an object and 'turning into an object' (Brom 1997). These categories represent a different unit of analysis for considering the underlying assumptions and implications of objectification. The effects of objectification may be in both categories the same.

The category of 'treating as an object' refers to the individual and/ or social attitude that people have towards others. It is used to indicate objectifying actions that do not take the inherent value of other groups of people and/ or animals into account; they are treated as if they were objects. The moral aspect especially focuses on the attitude behind these actions. It is the attitude that one is seen as an object which could lead to a denial of their interests and own nature (Brom 1997). Treating as an object can mean different things. It can mean that the objectified party is intentionally treated as an instrument for our use, but it can also mean that the objectified party is unintentionally reduced to an artefact, because of our ignorant (or naive) mind-set (Papadaki 2010). This refers to the Kantian notion of instrumentalisation, that is based on the dictum that we should never act in such a way that we treat humanity, whether in ourselves or in others, as a means only but always as an end in itself (Kant 1997). It also refers to a Kantian worldview, in which persons are subjects not objects. The person is a moral agent, autonomous and self-governing. An object is a nonperson, not treated as a self-governing agent. So, following that treating as an object refers to an individual and/ or social attitude, and given that our understanding of subjectivity is conflicted or in a process of transformation, we 
can now pose the question whether PLF transforms the attitude of people, and changes our understanding of the subjectivity of humans and animals.

The category of 'tuning into an object' refers to the transformative effects of a system. It is used to indicate actions where humans and animals are reduced to objects. It is a process in which an absolute adaptation to the needs of the objectifying people is facilitated by the purpose of a system upon which people act. The moral aspect focuses on a system outcome and reductionism; human and animals that are subjected to a system are reduced to objects (Brom 1997). The ethical problem is that the integrity or species typical norm of living beings (or species) is compromised when they are mainly understood as elements of a system (Thompson 2008b). They now become "living parts of a machinery" (Harfeld et al. 2016). In this sense, reductionism not only refers to the individual elements of a system, but also to their mutual relations. Discussions in animal ethics emphasise the transformative effects of an intensive animal husbandry system where production animals become an "absent referent" (Adams 1990) on people's moral radar, because of the system's purpose of a maximum yield and growth rate. The reductionist process of "de-animalisation" (Harfeld et al. 2016) indicates that production animals are taken out of their own evolutionary and environmental context. People involved in the system thereby reduce production animals to a 'production unit' or an artefact. So, following that 'turning into an object' refers to a system outcome and to reductionism, we can now pose the question whether PLF transforms the purpose of the system, and further detaches people from humans and animals that are subjected to the system.

\section{Analysis of Objectification beyond Kant}

The category of 'treating as an object' expands on Kantian concerns and the dominant moral codes of his time and place. As social life develops and changes in response to the concepts we share that describe and structure it, the concept of objectification has developed and changed with it (Radin 1991). Presently, objectification involves a set of notions in variable configuration that leads to denying one's humanity or inherent value. These notions include instrumentality, denial of autonomy, inertness, fungibility, violability, ownership, and denial of subjectivity (Nussbaum 1995).

In the analytical examples, given by Nussbaum (1995, pp. 279-283), the configuration of instrumentality, denial of autonomy, subjectivity-denial, treating as inert, and violability leads to harming a person's humanity, in the sense that a person's rational capacities are impaired. The set of notions involved leads to a situation in which a person becomes a passive creature solely to be used and violated by others. The configuration of treating as inert (lacking in agency and activity), fungible, and as a property (as owned) does not necessarily intervene with a person's rational capacities. The set of notions involved leads to a situation in which a person's humanity is ignored or not properly acknowledged (Nussbaum 1995, pp. 288-298).

Denying a person's humanity could mean in one situation that a person's humanity is harmed, while in another situation a person's humanity is ignored or not properly acknowledged. The configuration of instrumentality, denial of autonomy, subjectivity-denial, treating as inert, and violability is somewhat closer to Kant's original terminology, and therefore more absolute in its outcome. It leads to a situation in which a person is used and violated by others (a slippery slope to abuse). Objectification puts pressure on our conception of personhood (Radin 1996). For example, the abolition of slavery means that slaves are seen as human subjects again. A converse development is found regarding the objectification of women (and men), most notably in pornography, when they are treated as a body or a collection of body 
parts valued predominantly for its use (or consumption) by others. Anti-pornography feminists emphasise the repressive power of objectification, meaning that the harm to women's humanity is of a more permanent and pervasive nature, as it characterises every aspect of patriarchal societies (Dworkin 2000; MacKinnon 1987). This suggests that the human subject is a category of understanding that must undergo a transformation as well.

Although the analytical examples of Nussbaum (1995) are well informed on the heterogeneity of notions involved in particular relationship contexts, they are not purely introspective. Both Kant and Nussbaum lack meta-language to describe and understand objectification. This limitation entails that the meaning and use of objectification is exclusively analysed and understood from the perspective of the objectifier.

Feminist ethics provides a different way of thinking about the meanings and usages of objectification, one where the analytical components of Kant and Nussbaum are largely expunged. Central to the feminist picture of objectification is a switch in perspective from attitude of the objectifier to the objectified party (Bauer 2015). By tracking the experiences of the objectified party, the feminist picture extends on rationalist abstractions. The epistemological source of theorising about the nature, motives and consequences of objectification now shifts to the affected persons' experiences of objectification (Brabeck and Ting 2000). The emphasis on experiences suggests the need for a focus on care, empathy, and the interdependence of persons (Gilligan 1982; Held 2006). Care ethics holds interpersonal relationship and care or benevolence as a virtue that is central to moral action (Sander-Staudt 2011). Care can be defined as the ongoing concern for the wellbeing and the constructive development of the one caring, the one or ones cared for, and the relationship (Hawk 2011). It assumes relationships which are bound by mutual interdependence. This implies a duty of care for other human beings not because they can or someday may care for us, but because they are dependent on us just like we are (or have been) dependent on other human beings.

\section{Treating as Objects in Livestock Production}

For neo-Kantian ethicists, the range of non-human beings (or animals) who have an inherent value would include all those who are "subject-of-a-life" (Regan 2004) or those who can experience their own lives subjectively. While animals may not have discursive capacities (and to the extent they have, they escape to our understanding) and fullfledged (human-like) autonomy, they do have preference autonomy that needs to be taken into consideration (Korsgaard 2013; Regan 2004). Thus, animal ethicists have argued that animals indeed have moral status and preference autonomy and that their objectification can therefore be problematic. If our understanding of subjectivity is conflicted or in a process of transformation, then so is our understanding of objectification (Radin 1996). This dynamic of conflict and transformation also applies to our understanding of animals, their subjectivity, and hence their objectification.

Nussbaum's (1995, pp. 288-298) analytical example of treating as inert (lacking in agency and activity), fungible, and as a property (as owned) resonates with the conventional industrial farming context. It leads to a situation where the intrinsic value of production animals is ignored or not properly acknowledged; they are subjected to instrumentalisation. The industrial farming context is, in a sense, similar to other work-related contexts where we must use other people's skills, company and bodies. There are relationships in the context of which treating as an object is less problematic, for example if the objectified party can walk away (as in a labour contract) at reasonable costs. The moral assessment would then, inter alia, depend on the 
availability of an exit option and the costs of exiting (which can be prohibitive, e.g. when the objectified party depends on the labour income or the continuation of a marriage).

The question that arises at this point is what dimensions of 'treating as an object' already exist in conventional industrial livestock farming. Firstly, production animals are by now instrumentalised which follows from Nussbaum's analytical examples. Production animals are treated as own-able, fungible, and inert. Their intrinsic value is ignored or not properly acknowledged. This is a non-reductive objectification (Papadaki 2010), because it does not necessarily intervene with the animal's inherent value. The degree of (un-)intentional objectification (Papadaki 2010) depends on the context of the farmer-animal relationship. Secondly, production animals are treated as lacking autonomy, which is a Kantian notion. Lacking autonomy implies a duty of care, because of "our own self-assumed action in generating the production animal's dependency" (Engster 2006). Care ethics focuses on the way we actually treat animals that are dependent upon us. This offers a ground for improving the wellbeing of animals, as it brings our moral attention to the relationships we have with animals and the quality of life we provide for them (Engster 2006). The practice of care involves values of attentiveness, responsibility, competence and responsiveness ${ }^{1}$ (Anthony 2012; Parton 2003).

Following the neo-Kantian approach to objectification the question is whether PLF supports or undermines a practice of care. This implies the proposition that if care is sufficiently implemented within the PLF system, then PLF has a less reducing effect than when care is insufficiently implemented within the PLF system. This is a 'treating as' proposition, because the unit of analysis refers to transformation within a system.

When considering the implications of care ethics in conventional industrial livestock farming, few questions have immediate and practical importance for PLF. Care ethics assumes relationships that are bound by mutual interdependence. Although animals generally cannot inform humans on the care they need to survive, develop, and avoid or alleviate pain, care theory demands that any group of animals that is raised by human beings is treated in caring ways (with the necessary preconditions, such as animal welfare) (Engster 2006). Methodologically, the ethics of care starts from the proposition that we must recognise that the 'other' has a nature of her own that needs to be respected. ${ }^{2}$ Feminist ethicists restore the notions of sympathy, empathy and compassion to the philosophical debate and propose to validate them as authentic modes of knowledge. In practice, the animal's body language, such as eye movement, facial expression or tone of voice then become important (Donovan 2006). This implies a different form of science and thinking about animals in PLF. However, studies on specific human-animal relationships in farming have tended to be anthropocentric, centring on the human experience of animals and on human practices even if they imply an animal subjectivity. More recent work, on the other hand, focuses on the 'close' relationships with animals experienced by different types of farmer, describing also how they enter into seemingly intersubjective relationships with such animals (Holloway 2007).

Expanding on care ethics, feminist animal care theory proposes a social and dialogical mode of reasoning which departs from an understanding and appreciation of what is different from oneself rather than reshaping (in case of animals) that difference to conform to one's human based preconceptions (Donovan 2006). Knowing is also conceived of as a social and

\footnotetext{
${ }^{1}$ Some argue that Kant's integration of animal suffering into the very core of his virtue ethics may also open the door for an enlightened animal ethics based on human responsibility. For example Baranzke (2004).

${ }^{2}$ In case of animals, an exclusive focus on animal welfare is based on a utilitarian approach to animal ethics, in particular the welfarist strain of utilitarianism, which backgrounds neo-Kantian concerns about 'respect' to animals.
} 
political process where the recipient of care is not an 'object to be known' but a sentient being who we listen to and who we try to understand and communicate with (Sevenhuijsen 1998). This approach contrasts to an extent with those that have placed emphasis on human's practical wisdom or phronesis (Aristotle 1976; in Harfeld et al. 2016), implying that humans need to experience communality between oneself and the ecological environment in order to make sound judgements regarding the treatment of animals.

\section{Turning into Objects in Livestock Production}

In general, we can see that objectification is a deontological concept that is critical of narrow views on animal welfare without necessarily questioning animal production per se. When considering the debate over the intensification of animal production, it is argued that it is possible to uphold a decent level of animal welfare in intensive production systems and that the best way to promote animal welfare is to reform rather than to reject intensive animal production (Fraser 2008). This discussion does not fundamentally question the morality of intensive livestock production in general (Sandøe 2008). The ethical acceptability of a specific farming system is, rather, turned into an empirical question about the effects on the animals involved, and the analytical focus is on the ethical consequences of specific technicalorganisational arrangements. In response, animal welfare science has been criticised for creating an illusion of win-win solutions which enhance both animal welfare and production efficiency, while in reality marginal welfare improvements merely served to perpetuate a system that instrumentalises animals (Harfeld et al. 2016).

The question that arises at this point is what dimensions of 'turning into an object' already exist in conventional industrial livestock farming. Philosophical and empirical discussions have distinguished several dimensions of objectification in livestock farming: de-animalisation, commodification, alienation, and quantification. For animal ethicists, these processes become morally problematic when people cannot see and know that animals are present - and hidden - in the livestock production system (Harfeld et al. 2016); when animals are invisible or absent referents (Adams 1990) in the institutional and technological production environment (Thompson 2006); when the animal is alienated from its relationship to the ecological environment, its species being, and the farmer (Stuart et al. 2013); and when a quantitative and positivist paradigm leads to reductionism that denies the animal's qualitative experiences and disregards the individual qualitative differences between animals (Rollin 2006).

1. In discussing de-animalisation, the livestock production context is important. Deanimalisation indicates that production animals are taken out of their of their own evolutionary and environmental context, whereby people involved in the animal production system reduce them to a 'production unit' or an artefact. This reductive process is facilitated by the system's purpose of a maximum yield and growth rate (Harfeld et al. 2016).

2. In discussing commodification, the industrial farming context is important. Commodification involves institutional and technological commodification. Institutional commodification is facilitated by the institutional environment, such as food supply chains, around the animal sourced commodity in question. Technological commodification refers to the selection of species of farmed animals and the methods of animal rearing. This is enabled by genetics-based animal breeding and biotechnology. Animals subjected to the agro-food 
system are materially transformed in order to comply with the requirements of the production process and economic expectations (Thompson 2006).

3. In discussing alienation, the political and social context is important. Alienation originates from Marx' (1978 [1844]) conception that under capitalist systems of production, workers are alienated from their product, productive activity, species being, and other humans. For Marx, the labour process in capitalist societies inhibits the unfolding of latent potentialities and turns the powers and capacities of labourers against themselves. In livestock farming, alienation has been applied to analyse the position of cows in dairy farming and the transformative effects of robotic milking systems (Stuart et al. 2013).

4. In discussing quantification, the scientific and process management context is important. Quantification denotes a quantitative and positivist paradigm in science and thinking about animals, which is underlying to the implementation of quantifiable and repeatable control systems and to the standardisation of processes in livestock farming (Rollin 2006).

Thus, the question is whether PLF strengthens or disrupts the reductionist system of conventional industrial livestock farming. PLF has been developed within this system, which suggests that it has been developed to strengthen the system of conventional industrial livestock farming. The question now becomes: can PLF have transformative effects, will it disrupt the human-animal relationship? This question shifts objectification from 'treating as an object' to 'turning into an object', because the unit of analysis refers to the transformative effects of the PLF system.

\section{Objectification by PLF}

Building on the analysis of the concept of objectification, its application in animal ethics and the central components in care ethics as a potential remedy, we can now assess the objectifying principles of PLF. This assessment draws on literature on computers and electronics, animal biometrics, and animal sciences, and draws as well on EU-PLF project deliverables and PLF conference proceedings. The implications of objectification by PLF will be organised along the conceptual framework outlined in Fig. 2.

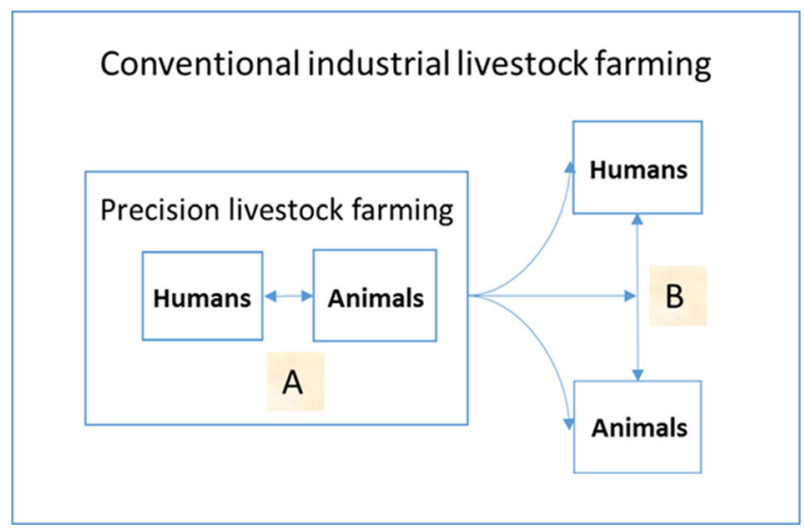

Fig. 2 Conceptual framework 
Figure 2 shows the two meanings and usages of objectification distinguishable at two systemic levels influencing the human-animal relationship in different ways. The category of 'treating as an object' (indicated as A) is situated at the inner systemic level of PLF. The specific question that belongs to this unit of analysis is whether PLF transforms the attitude of farmers towards animals, and changes our understanding of the subjectivity of humans and animals. The category of 'turning into an object' (indicated as B) is situated at the outer systemic level of conventional industrial livestock farming. The specific question that belongs to this unit of analysis is whether PLF transforms the purpose of the system, and further detaches people from humans and animals that are subjected to the system.

The category of 'treating as an object' refers to the individual and/ or social attitude that livestock farmers have towards their production animals within the PLF system. What influences attitude (and practices) are the functionalities of the PLF technology and their implicit norms and values. In PLF, the value of user convenience results in different norms that focus on remote control, standardisation of methods for analysis, real-time data tracking and analysing, and data transparency. These norms guide criteria for monitoring and control of the individual animal and/or groups of animals, but they do not necessarily concentrate on criteria that reflect the best interests of animals. Care may be strengthened by the use of sensors. Both care and sensor technology involve values of attentiveness, responsibility, competence and responsiveness. Sensor technology enables the collection of data continuously over time in and around the animal. The accompanying software provides the farmer with a timely attention on the smartphone when a particular animal requires an intervention. These type of interventions may be guided by norms and criteria for improving the wellbeing of animals.

The use of digital devices, such as sensors and robotic process automation in PLF, involves the substitution of labour for capital. Robots take over the farmers' practical day-to-day tasks such as milking, feeding, manure scraping, egg collecting and packaging. While robots perform these tasks accurately and irrespective of the time of the day, they may also take over the mental activities and analytical skills of the farmer. PLF is an example of the digital era in which we now live, also referred to the "second machine age" (Brynjolfsson and McAfee 2014). This era is about digital machines that deliver brain power, such as computers, the Internet, smart phones, artificial intelligence, and digital platforms. Following the pattern of the 'first machine age' in England at the end of the eighteenth century when steam engines replaced the muscle power of humans and animals, the question now becomes whether the dynamics of the 'second machine age' also changes the relationship to what we do, who we are and how we produce our food. The ultimate question is whether the dynamics of the digital era changes our understanding of the subjectivity of humans and animals involved in the food system.

The category of 'turning into an object' refers to the transformative effects of the PLF system on the human-animal relationships within the conventional industrial livestock farming system. PLF mediates the human-animal relationship, implying that farmers and animals become subjected to new expectations. In addition to animal-sourced products, which can be seen as the instrumental artefacts that PLF brings forth, PLF also produces data that steer behaviour. Such data include farm economic performance, farm environmental performance (e.g. emissions of ammonia), and farm animal performance (e.g. output quality, growth rates, diseases). Stakeholders in the value chain with strong commercial interests are particularly likely to use these data to gain market power. The sense of behaviour that these data create decreases free riding or other opportunistic behaviours of farmers, thus imposing compliance. This compliance, enhanced by the standardisation of methods for analysis in PLF, may force 
farmers to reduce their animals to an absolute adaptation to production criteria and economic expectations of the technological and institutional production environment.

PLF redefines the notion of care, in terms of data transparency, standardisation of methods for analysis, real-time collection and processing of data, remote control, and the use of digital platforms. What redefines the care relationship between the farmer and the animal is not only the sensor technology that facilitates the real-time collection and processing of data, but also a computer controlled intelligence that arises around animals. This new type of intelligence, characterised as artificial intelligence and algorithmic formalisation, leads to a more refined diagnostics of data. The sense of behaviour that this new intelligence creates increases the instrumental reasoning of the farmer where the pursuit of knowledge is intertwined with the pursuit of control. The pursuit of control, enhanced by the insights from animal sciences and process engineering, may force farmers to focus on the prevalence of diseases, the extension of the animal's life-span, and the reduction of medical costs of antibiotics. The animal's qualitative experiences and the individual qualitative differences between animals may become underexposed when farmers reduce their animals to a tracking device or 'quantified animal'.

The widening scope and organisation of PLF allows for the participation of different groups of actors. This also requires a redistribution of responsibilities between stakeholders concerning privacy and data ownership issues. These issues pertain to the social effects by PLF, and additionally raise the question whether farmers are able to control and understand PLF's underlying algorithms and withstand PLF's unpredictable outcomes.

\section{Conclusion}

The ongoing implementation of novel PLF technologies at farm level and throughout the value chain emphasises the need to take into account what effects the PLF system will have on human-animal relationships in conventional industrial livestock farming. This focus on objectification and PLF reveals that there are two distinct meanings and usages of objectification being played out in conventional industrial farming: 'treating as an object' and 'turning into an object'. The category of 'treating as an object' refers to the individual and/ or social attitude that people have towards others, whereas the category of 'turning into an object' refers to the transformative effects of a system. Although we have focused on PLF, a comparatively novel technology, particular dimensions of 'turning into an object' in livestock farming have already been scrutinised before the rise of PLF as (1) animals as invisible parts of an intensive animal husbandry system, when they are taken out of their own evolutionary and environmental context; (2) animals as commodities, when there is an absolute adaptation to production criteria and economic expectations of the technological and institutional production environment; (3) the concept of animal's alienation from its relationship to the ecological environment, its species being, and the farmer; and (4) a quantitative and positivist paradigm in science and thinking that denies the animal's qualitative experiences and disregards the individual qualitative differences between animals.

The line of reasoning demonstrated above refers to a deontology that looks beyond a functional understanding of animal welfare within given production systems (and their trajectories) and points to the overall socio-political and relational context. The limits of welfarist approaches imply that their associated technical-organisational arrangements in conventional industrial livestock farming tend to actually support and justify continued animal instrumentalisation and objectification. From a system's perspective, industrial agriculture 
could as well be critically evaluated as a commodity-producing 'black box' with convenience and abundance as guiding values. These values accentuate that the fundamental character of food is as technological artefact or device (Thompson 2008a). In this sense, food production is reduced to appropriating a uniform commodity or an item of convenience. People do not develop a relationship with the food that they eat. Therefore, food remains alien, impersonal, and isolated (Anthony 2012). This indicates the importance of taking into account wider (socio-political, cultural and geographical) contexts in which the treatment of production animals and the human-animal relationships are subjected to change (Holloway et al. 2014).

We do not argue that an emerging technology such as PLF causes further animal objectification per se. Instead, we suggest the proposition that if care is sufficiently implemented within the PLF system, then PLF has a less reducing effect than when care is insufficiently implemented within the PLF system. This is a 'treating as' proposition, because the unit of analysis refers to transformation within a system. One way of viewing PLF is thus to see it as a ground for improving the wellbeing of animals, because the technology highlights the care for the individual animals and their quality of life. On the other hand PLF mediates the humananimal relationship in conventional industrial livestock farming, implying that farmers and animals become subjected to new expectations. PLF redefines the notion of care, in terms of data transparency, standardisation of methods for analysis, real-time collection and processing of data, remote control, and the use of digital platforms. Therefore PLF requires a redistribution of responsibilities within a wider scope of relations in the value chain.

Although the implications of objectification by PLF can be described in these terms, care ethics allows us to focus on a social and dialogical mode of reasoning that departs from an understanding and appreciation of what is different from oneself. An example of this is the position of the livestock farmer who easily becomes an invisible and anonymous part of the PLF system. While the notion of 'care recipient' hitherto referred only to livestock animals, it now also applies to livestock farmers who are not 'objects to be known' but sentient beings who we should listen to and who we should try to communicate with. This requires an understanding of the farmers' changed experiences and ways of being. Farmers who are subjected to the PLF system are reduced to being a part of an encompassing farm management system that is embedded in markets and agricultural policy.

Differences in farmers' life histories and personal circumstances, farm's business structures and their relations with relevant stakeholders in the value chain must therefore be taken into account. For some, intensive use of PLF technologies is key of their farming practices. For others, they may be unaware of what PLF technologies are available, or unable or maybe unwilling to fully engage with the PLF control system. Finally, as individuals, consumers and the general public do not develop a relationship with the livestock farmers who are providing both data to the PLF system, and animal-sourced products to the value chain, these farmers remain alien, impersonal and isolated. The requirements and intuitions of the ethics of care discussed in this paper provide some likely suggestions for food industry and ICT companies involved in developing digital platforms or data hubs through which they relate to farmers and their livestock. For example, they should enter into a conversation with famers about the purpose and use of digital platforms, and reflect with them on the uncertainties and risks these new relationships through digital platforms would bring.

This raises important questions for future research. First, empirical research is needed to test whether the introduction of PLF into farming system marginalises the kind of practices advocated by care ethics and whether the different types of objectification of animals identified through our analysis are indeed observed in practice. Here cross- 
country and cross-farm variation, e.g. between different sub-sectors and farm types and sizes, would be of particular interest. Second, the conceptual framework developed here should be socially validated through discussions with practitioners. Third, and building on the previous two steps, our conceptual framework could be used to guide the design of animal husbandry systems that combine the possibilities of PLF with the ethical requirements and intuitions of the ethics of care approach.

Open Access This article is distributed under the terms of the Creative Commons Attribution 4.0 International License (http://creativecommons.org/licenses/by/4.0/), which permits unrestricted use, distribution, and reproduction in any medium, provided you give appropriate credit to the original author(s) and the source, provide a link to the Creative Commons license, and indicate if changes were made.

\section{References}

Adams, Carol. 1990. The sexual politics of meat: A feminist-vegetarian critical theory. New York: Continuum. Anthony, Raymond. 2012. Building a sustainable future for animal agriculture: An environmental virtue ethic of care approach within the philosophy of technology. Journal of Agricultural and Environmental Ethics 25 (2): 123-144.

Aristotle. 1976. Ethics. Penguin Classics.

Banhazi, Thomas M., and John L. Black. 2009. Precision livestock farming: A suite of electronic systems to ensure the application of best practice management on livestock farms. Australian Journal of Multidisciplinary Engineering 7 (1): 1-14.

Banhazi, Thomas M., L. Babinszky, V. Halas, and M. Tscharke. 2012. Precision livestock farming: Precision feeding technologies and sustainable livestock production. International Journal of Agricultural and Biological Engineering 5 (4): 54-61.

Baranzke, Heike. 2004. Does Beast Suffering Count for Kant: A Contextual Examination of $\S 17$ in The Doctrine of Virtue. Essays in philosophy 5 (2):4.

Bauer, Nancy. 2015. How to do things with pornography. Cambridge: Harvard University Press.

Berckmans, Daniel. 2008. Precision livestock farming (PLF). Computers and Electronics in Agriculture 64 (1).

Berckmans, Daniel. 2014. Precision livestock farming technologies for welfare management in intensive livestock systems. Scientific and Technical Review of the Office International des Epizooties 33 (1): 189-196.

Berckmans, Daniel, and Joris Vandermeulen. 2013. Precision livestock farming '13. In Papers presented at the 6th European Conference on Precision Livestock Farming. Leuven, Belgium.

Bewley, Jeffrey W. 2016. Update on use of sensors on dairy farms. In Precision dairy farming 2016, ed. C. Kamphuis and W. Steneveld, 41-45. Wageningen: Wageningen Academic Publishers.

Bos, A.P. Bram. 2008. Instrumentalization theory and reflexive design in animal husbandry. Social Epistemology 22 (1): 29-50.

Bos, Jacqueline, and Geert Munnichs. 2016. Digitalisering van dieren. Den Haag: Rathenau Instituut.

Brabeck, Mary M, and Kathleen Ting. 2000. Feminist ethics: Lenses for examining ethical psychological practice. Practicing feminist ethics in psychology 17-35.

Bramley, Rob R.V. 2009. Lessons from nearly 20 years of precision agriculture research, development, and adoption as a guide to its appropriate application. Crop and Pasture Science 60 (3): 197-217.

Brom, Frans W. A. 1997. Onherstelbaar verbeterd: Biotechnologie bij dieren als een moreel probleem. Van Gorcum.

Brynjolfsson, Eric, and Andrew McAfee. 2014. The second machine age: Work, progress and prosperity in a time of brilliant technologies. New York: WW Norton \& Company.

Daugbjerg, Carsten, and Peter H. Feindt. 2017. Post-exceptionalism in public policy: Transforming food and agricultural policy. Journal of European Public Policy: 1-20.

Donovan, Josephine. 2006. Feminism and the treatment of animals: From care to dialogue. Signs: Journal of Women in Culture and Society 31 (2): 305-329.

Dworkin, Andrea. 2000. Against the male flood: Censorship, pornography, and equality. In Oxford readings in feminism: Feminism and pornography, ed. D. Cornell, 19-44. Oxford: Oxford University Press.

Engster, Daniel. 2006. Care ethics and animal welfare. Journal of Social Philosophy 37 (4): 521-536. 
EU-PLF. 2017. Smart farming for Europe. Value creation through Precision Livestock Farming. http://www.euplf.eu/index.php/objectives/. Accessed 30 August 2017.

Feenberg, Andrew. 1999. Questioning technology. London: Routledge.

Feenberg, Andrew, and Michel Callon. 2010. Between reason and experience: Essays in technology and modernity. Cambridge: MIT Press.

Fraser, David. 2008. Animal welfare and the intensification of animal production. In The ethics of intensification, ed. Paul B Thompson, 167-189. Springer.

Frost, A.R., C.P. Schofield, S.A. Beaulah, T.T. Mottram, J.A. Lines, and C.M. Wathes. 1997. A review of livestock monitoring and the need for integrated systems. Computers and Electronics in Agriculture 17 (2): $139-159$.

Furner, Jonathan. 2004. Conceptual analysis: A method for understanding information as evidence, and evidence as information. Archival Science 4 (3): 233-265.

Gilligan, Carol. 1982. In a different voice. Cambridge: Harvard University Press.

Harfeld, Jes Lynning, Cécile Cornou, Anna Kornum, and Mickey Gjerris. 2016. Seeing the animal: On the ethical implications of De-animalization in intensive animal production systems. Journal of Agricultural and Environmental Ethics 29 (3): 407-423.

Hawk, Thomas F. 2011. An ethic of care: A relational ethic for the relational characteristics of organizations. In Applying care ethics to business, eds. Maurice Hamington, and Maureen Sander-Staudt, 3-34. Issues in Business Ethics, vol. 34. Dordrecht: Springer.

Held, Virginia. 2006. The ethics of care: Personal, political, and global. Oxford University Press.

Holloway, Lewis. 2007. Subjecting cows to robots: Farming technologies and the making of animal subjects. Environment and Planning D: Society and Space 25 (6): 1041-1060.

Holloway, Lewis, Christopher Bear, and Katy Wilkinson. 2014. Robotic milking technologies and renegotiating situated ethical relationships on UK dairy farms. Agriculture and Human Values 31 (2): 185-199.

Kamphuis, Claudia, and Wilma Steneveld. 2016. Precision dairy farming 2016. Wageningen: Wageningen Academic Publishers.

Kant, Immanuel. 1997. Formula of humanity. Groundwork of the metaphysics of morals, ed. M. Gregor. Cambridge: Cambridge University Press.

Korsgaard, Christine M. 2013. Kantian ethics, animals, and the law. Oxford Journal of Legal Studies 33 (4): 629-648.

Kühl, Hjalmar S., and Tilo Burghardt. 2013. Animal biometrics: Quantifying and detecting phenotypic appearance. Trends in Ecology \& Evolution 28 (7): 432-441.

Loor, Juan J., Giuseppe Bertoni, Afshin Hosseini, John R. Roche, and Erminio Trevisi. 2013. Functional welfare-using biochemical and molecular technologies to understand better the welfare state of peripartal dairy cattle. Animal Production Science 53 (9): 931-953.

Lowe, Philip, Peter H. Feindt, and Hilkka Vihinen. 2010. Introduction: Greening the countryside? Changing frameworks of EU agricultural policy. Public Administration 88 (2): 287-295.

MacKinnon, Catharine A. 1987. Feminism unmodified: Discourses on life and law. Cambridge: Harvard University Press.

Marx, Karl. 1978 [1844]. Economic and philosophic manuscripts of 1844. In The Marx-Engels reader, ed. R.C. Tucker, 66-125. New York: W.W. Norton.

Nieuwe Oogst. 2017. Datahub verbetert digitaal verkeer melkveehouder. https:/www.nieuweoogst. nu/nieuws/2017/05/16/datahub-verbetert-digitaal-verkeer-melkveehouder. Accessed 30 August 2017.

NRC. 2012. Een gezondere koe voor één cent meer. https:/www.nrc.nl/nieuws/2012/02/17/een-gezondere-koevoor-een-cent-meer-12167524-a1114151. Accessed August 302017.

Nussbaum, Martha C. 1995. Objectification. Philosophy \& Public Affairs 24 (4): 249-291.

Papadaki, Lina. 2010. What is objectification? Journal of Moral Philosophy 7 (1): 16-36.

Parsons, David J., Darren M. Green, Charles P. Schofield, and Colin T. Whittemore. 2007. Real-time control of pig growth through an integrated management system. Biosystems Engineering 96 (2): $257-266$.

Parton, Nigel. 2003. Rethinking professional practice: The contributions of social constructivism and the feminist 'ethics of care'. British Journal of Social Work 33 (1): 1-16.

Radin, Margaret Jane. 1991. Reflections on objectification. Southern California Law Review 65: 341-345.

Radin, Margaret Jane. 1996. Contested commodities. Harvard University Press.

Regan, Tom. 2004. The case for animal rights. Berkeley: University of California Press.

Rollin, Bernard E. 2006. Science and ethics. Cambridge: Cambridge University Press.

Sander-Staudt, Maureen. 2011. Care ethics. In Internet Encyclopedia of Philosophy, eds. J. Frieser, and B. Doweden.

Sandøe, Peter. 2008. Re-thinking the ethics of intensification for animal agriculture: Comments on David Fraser, animal welfare and the intensification of animal production. In The Ethics of Intensification, ed. Paul B Thompson, 191-198. Springer. 
Sevenhuijsen, Selma. 1998. Citizenship and the ethics of care: Feminist considerations on justice, morality, and politics. London: Routledge.

Smart Dairy Farming. 2017. Available smart data applied on the farm. https://smartdairyfarming.nl/en/. Accessed August 302017.

Stuart, Diana, Rebecca L. Schewe, and Ryan Gunderson. 2013. Extending social theory to farm animals: Addressing alienation in the dairy sector. Sociologia Ruralis 53 (2): 201-222.

Thompson, Paul B. 2006. Commodification and secondary rationalization. In Democratizing technology: Andrew Feenberg's critical theory of technology, ed. T.J. Veak, 112-135. Albany: State University of New York Press.

Thompson, Paul B. 2008a. The ethics of intensification: Agricultural development and cultural change. Springer.

Thompson, Paul B. 2008b. The opposite of human enhancement: Nanotechnology and the blind chicken problem. Nanoethics 2 (3): 305-316.

Wakker Dier. 2010. Vijf voor twaalf voor de Nederlandse veehouderij. https:/www.wakkerdier. nl/uploads/media_items/rapport-melkveesector-vijf-voor-twaalf.original.pdf. Accessed 30 August 2017.

Wathes, Christopher $\bar{M}$., Helle Halkjær Kristensen, Jean-Marie Aerts, and Daniel Berckmans. 2008. Is precision livestock farming an engineer's daydream or nightmare, an animal's friend or foe, and a farmer's panacea or pitfall? Computers and Electronics in Agriculture 64 (1): 2-10.

\section{Affiliations}

\section{Jacqueline M. Bos ${ }^{1} \cdot$ Bernice Bovenkerk $^{1} \cdot$ Peter H. Feindt ${ }^{2} \cdot$ Ynte K. van Dam $^{1}$}

1 Department of Social Sciences, Wageningen University \& Research, PO Box 8130, 6700 EW Wageningen, The Netherlands

2 Albrecht Daniel Thaer-Institut für Agrar- und Gartenbauwissenschaften, Humboldt-Universität zu Berlin, Unter den Linden 6, 10099 Berlin, Germany 